would be cumbrous, for the obvious reason that in a given paper, much valuable work is recorded which served only as a means to the end treated of ; this work, therefore, lies hidden under a title which does not even remotely refer to it.

On the other hand, the compilation of lists of papers on particular subjects is franght with no great difficulty, and would be of very great value. While the preparation of such minor indexes founded on the Royal Society Catalingue may be left to private enterprise, great advantage would, I think, be derived from some united action in the matter. I have myself made considerable headway with a classified list of papers on the subject which chiefly interests me, and which perhaps is best named Molecular Physics. This work necessitates my going through the whole catalogue for the sake of comparatively few papers, and I am further-obliged to copy out the titles of, and references to, the papers I require. Now, if a movable copy of the Royal Society's Index were made as suggested by $\mathrm{Mr}$. Garnett (NATURE, vol. xx. p. 554), and the different entries classified in sciences, these difficulties would be removed; $\mathrm{Mr}$. Garnett, however, underrates the cost of preparing such a movable index, which would be large enough to deter many "gentlemen with leisure" from undertaking it. This work, therefore, must be carried out either by the Royal Society, or by a committee of those who take an interest in the subject; when completed the index could be distributed among those willing to undertake the subsequent arrangement in subjects.

There is another suggestion which I should like to make before closing this letter. Every month as it slips by adds rapidly to the enormous accumulation of scientific papers; unless these are catalogued and classified immediately they are published, the subject catalogue will never be satisfactory. What is wanted, then, is the publication (say every quarter) of a complete list of the scientific papers published during that period. I am aware that, as mentioned by Mr. Garnetr, many such lists now appear, but none of them can be trusted as complete records.

If, however, a list were published "by authurity" (for example, by the British Museum or the Royal Society), scientific men all over the world would send the titles of their papers to be entered in it, and it would soon be recognised that those who did not do so would stand a cbance of rendering their work useless to those who travel after them along the same paths.

Science Schools, November 3

F. D. BROWN

\section{Easter Island}

IN the very interesting review of Mr. Wallace's "Australasia," in NATURE, vol. xx. p. 598, there is a passing reference to some views of my own concerning the stone images of Easter Island. The nature of the inferences that may be drawn in this case is not, I think, generally understood ; and without wishing to give the subject more importance than it deserves, I shonld be glad if you could allow me space for a few words upon it.

Any positive ideas about the people who made them can hardly be got from the images themselves. They are rudely carved and ugly, and no existing race attempts to make anything really like them. But they are very numerous and very large; many of them weigh twenty tons, some probably two or three times as much. They have been quarried from a volcanic hill, conveyed several miles, and set upright upon pedestals, on massive stone terraces of great length. Work of this kind requires a definite amount of labour and strengtb. The amount available depends on the population. The population of a solitary island inhabited by savages is strictly limited by its area ; the area of Easter Island is not more than forty square miles. There is, I believe, no known example in which an island of this kind supports, in an uncivilised state, more than fifty persons to the square mile. This is double the usual limit among savages.

Two thousand, therefore, would be the extreme limit of the population of Easter Island, unassisted from without; it has not more than half this number at present. In a population of 2,000 there are about 500 adult males, and we are to consider whether the work could have been done or even thought of with this amount of physical strength. It is, doubtless, quite impossible. A much larger number of people, or the help of civilised appliances, must necessarily have been at hand; but neither of these could be at hand without external help, and this could only reach the island across two thousand miles of ocean.

This is the really important point in this chain of inferences. We are led by what $I$ think are inevitable steps to the conclusion that when these images were made there was a nation some- where whose ships navigated the Pacific Ocean in such a manner that Easter Island could for a long period be supported as a colony.

I will not speak here of the anthropological bearings of this inference. Let me, however, enter a gentle protest against the sentence in which your reviewer speaks of "the accepted scientific position that primitive man was savage."

No doubt this is at present the belief of the majority of those who express their views; but there are names of great weight on the other side, and, considering what our actual knowledge of "primitive man" amounts to just now, it is rather hard upon science to make her responsible for our speculations.

November 3

ALBERT J. MOTT

\section{Animals and the Musical Scale}

IN a criticism in the Examiner of a book of mine on the " Theory of Music," the writer says :-

"We can hardly agree with Dr. Pole's view as to the essential artificiality of the diatonic scale, especially in the light of many facts collected by Mr. Darwin and other good observers. It is now almost certain that several of the lower animals have a very fair notion of the scale, and employ notes almost, if not quite, identical as to interval with our own."

If any of your readers can bring forward well authenticated facts of the kind they will be very interesting.

Athenæum Club, October 29

William Pole

\section{John Miers}

IN your notice of the late venerable botanist, Mr. John Miers, in NATURE, vol. xx. p. 614, it is stated that "to the last he disbelieved in the action of the pollen and of the pollen-tube in the formation of the embryo-plant."

It is possible that the writer may have had some farther warrant for this statement than the views published by $\mathrm{Mr}$. Miers in his memoir on Myostoma (Trans. Linn. Soc., xxv. pp. $461-475$ (1866), but it is scarcely borne out by them

Mr. Miers's position as there expressed is that "it is not the pollen-tube, but simply the fluid-material contained in the pollen-grain, and emitted from its tubes, which is the direct agent in the process of fertilisation."

Whatever may be thought of this view, it is far from justifying the strong statement that in supporting it Miers "disbelieved in the action of the pollen."

October 28

[It would certainly have been more explicit had we added the word "tube" to pollen. At p. 468 of the paper cited by $D_{\text {r. }}$. Trimen, Mr. Miers remarked "that the very important fact alluded to (the impact of the pollen-tube on the embryo-sac and the consequent fertilisation of the ovule) has not yet been satisfactorily proved." This was written in 1866 . In the same paper "we have it demonstrated that in this case (Myostoma) the theory of the application of pollen-tubes for the fertilisation of its ovules is distinctly disproved."-ED.]

\section{The Howgate Arctic Expedition}

Capt. Howgate, U.S.A., having for some years past fruitlessly endeavoured to obtain the comparatively small grant of 50,000 dollars from the American Government, for the purpose of carrying out his peculiar scheme of Arctic exploration, by forming a colony of active and experienced men, with a few families of Eskimos, at the coal-bed discovered some years ago in Lady Franklin Bay, Smith Sound, lat. $8 \mathrm{I}^{\circ} \mathrm{N}$., has determined to equip a private expedition on a smaller scale with this object.

A screw-steamer of about 140 tons (cargo measurement) has been bought for Capt. Howgate in the Clyde, has been refitted there, but not strengthened for ice navigation, which is to be done at Washington, and will, wind and weather permitting, sail for America on Tharsday, November 6.

As most of your readers probably already know, Capt. Howgate's intention is that the explorers, instead of living on board ship, shall pass the winter in wooden houses taken out on purpose in frames, to be set up near the coal-seam, the party to remain in this locality for two or more years, watching a favourable opportunity of smooth ice or open water to push northward, and occupying their time usefully in making scientific observations, which are still much wanted in that far north region. Balloons, the telegraph, and probably the telephone, may be brought into use. 